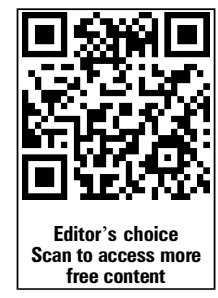

Department of Clinical Research, Institute of Cytology and Preventive Oncology (ICMR), Noida, Uttar Pradesh, India ${ }^{2}$ Department of Epidemiology, Institute of Cytology and Preventive Oncology (ICMR) Noida, Uttar Pradesh, India ${ }^{3}$ Institute of Cytology and Preventive Oncology (ICMR), Noida, Uttar Pradesh, India

\section{Correspondence to} Professor Ravi Mehrotra, Institute of Cytology and Preventive Oncology (ICMR), Plot 1-7, Sector-39, Noida 201301, Uttar Pradesh, India; rmehrotra@icmr.org.in

Received 7 April 2015 Accepted 16 May 2015

CrossMark

To cite: Parashari $A$, Singh $V$, Sehgal $A$, et al. BMJ Innov 2015;1:99-102.

\title{
AV Magnivisualizer: a low-cost screening technology for early detection of precancerous and early cancerous lesions of the uterine cervix
}

\author{
Aditya Parashari, ${ }^{1}$ Veena Singh, ${ }^{1}$ Ashok Sehgal, ${ }^{2}$ Ravi Mehrotra ${ }^{3}$
}

\begin{abstract}
Cervical cancer is a leading malignancy among women in developing countries. Screening based on visual techniques, including visual inspection (VI), VI with acetic acid (VIA) and VIA under magnification (VIAM), has been tested in different research settings and found to be useful. In the field settings of primary health centres, the only available light source is generally a tungsten bulb emitting yellow light attached to a torch or examination light. This type of light has a masking effect on the lesions in a pinkish mucosal background. Thus, an ideal light source with certain magnification is a highly desirable requirement for $\mathrm{VI}$ of the cervix for early detection of early and precancerous lesions. A portable, user-friendly, low-cost device (AV Magnivisualizer), which has a complete spectrum of visible light (white light) and interchangeable magnification, was developed by the authors. This instrument showed better sensitivity to detect significant precancerous lesions of the cervix compared with VIA ( $83 \%$ vs 54\%) without losing any specificity. Studies confirmed that the AV Magnivisualizer may replace a colposcope in settings where colposcopy facility may not exist. After studying the potential utilisation and usefulness of its ever-evolving role in screening and evaluation at a very low cost (approximately US\$160 per piece), the Government of India launched this instrument for widespread use. The Indian Council of Medical Research has recently completed the agreement for commercial production of the equipment. This article elaborates the development of the device and validation studies on this equipment in various settings.
\end{abstract}

\section{INTRODUCTION}

Cervical cancer is a leading malignancy among women in developing countries. Screening based on visual techniques has been tested in different research settings and found to be useful. At least two large randomised controlled trials from India have shown that screening based on a visual inspection of the cervix can reduce incidence and mortality from cervical cancer substantially, one in Tamil $\mathrm{Nadu}^{1}$ and another in Mumbai. ${ }^{2}$ These screening modalities, however, were tested in research settings, the studies being carried out by renowned investigators using funds from international agencies. For its widespread use in the community nationwide where the existing health infrastructure needs further strengthening/modifications as well as evolving a referral pattern from a primary to a tertiary healthcare system, a more pragmatic approach is needed.

\section{RATIONALE FOR THE DEVELOPMENT OF A LOW-COST INSTRUMENT}

Much of the primary healthcare system in India faces the problem of erratic electricity supply and uses an outdated lighting system of a tungsten bulb/torch emitting yellow light. Yellow light lacks the complete visible spectrum (colour temperature $4000-4500^{\circ} \mathrm{K}$ ). This spectrum masks many of the aceto-white areas, indicative of precancerous and early cancerous lesions, in a background of pinkish mucosa. In order to overcome 
these deficiencies, there is a need to use a light system which uses an in-built system that emits white light. White light has a complete balanced visible spectrum of light. This is likely to improve the sensitivity and specificity to detect precancerous and cancerous lesions of the cervix. This fact was supported by a previous study by our group ${ }^{3}$ in which 385 women were screened by both yellow and white light in the same sitting. This study clearly brought out the significance of visual examination of the cervix using white light; in addition to having a perfect correlation with colposcopy $(0.86$ for white light vs 0.53 for yellow light), white light enables selection of the correct biopsy site for biopsy.

\section{CHRONOLOGICAL SEQUENCE OF STEPS IN THE DEVELOPMENT OF A LOW-COST INSTRUMENT}

In order to overcome deficiencies in the existing health infrastructure even in the remotest possible village or forest habitat with no or erratic electricity supply, studies were initiated at the Institute of Cytology and Preventive Oncology for developing a portable instrument that could generate an uninterrupted source of white light. The sequential steps in the development of the final version of an optical instrument are given in table 1 . The first prototype, developed in 1997, consisted of a 2.5 dioptre single lens, a halogen bulb of 50 watts with a stainless steel body with an attached simple PVC handle. Difficulties were encountered in visualising the cervix and defining the lesions on account of the weak intensity of the light source. In addition, the light chamber used to get heated during clinical examination. As a result, a need was felt to modify this instrument. The instrument was thus modified to develop a second prototype in the year 2000. The use of a 100 watt halogen bulb significantly improved the intensity of light resulting in better visualisation of cervical lesions. However, the increased intensity of light also resulted in creating undesirable irregular shadow rings. A third prototype was developed in 2004 that took care of the shadow rings by integrating the halogen bulb with a mercury reflector fitted in the light chamber. Further improvement was made in this prototype by providing interchangeable lenses of 1,2 and 3 dioptre values, instead of a fixed single lens of 2.5 or 5 dioptres in earlier versions. In order to deal with the overheating of the light chamber, an aluminium body drilled with holes was used instead of the stainless steel body of the earlier version. The final version, the commercial model, was developed in 2009. This version included all modifications suggested by the clinical investigator (VS) in order to make it userfriendly. These modifications included a better grip of the instrument by using die-cast PVC (instead of a

Table 1 Sequential steps in the development of the final version of the magnivisualizer

\begin{tabular}{|c|c|c|c|c|c|}
\hline $\begin{array}{l}\text { Prototype } \\
\text { with year }\end{array}$ & Light source & Magnification & Main body & $\begin{array}{l}\text { Deficiency } \\
\text { observed }\end{array}$ & Improvement \\
\hline $\begin{array}{l}\text { First prototype } \\
\text { (1997) }\end{array}$ & Halogen bulb of 50 watt & 2.5 dioptre single lens & $\begin{array}{l}\text { Stainless steel body with a } \\
\text { simple PVC handle for } \\
\text { wiring }\end{array}$ & $\begin{array}{l}\text { Weak light intensity } \\
\text { and low magnification } \\
\text { Heating of light } \\
\text { chamber }\end{array}$ & - \\
\hline $\begin{array}{l}\text { Second } \\
\text { prototype } \\
(2000)\end{array}$ & $\begin{array}{l}\text { Halogen bulb of } 100 \\
\text { Watt }\end{array}$ & 5 dioptre single lens & $\begin{array}{l}\text { Stainless steel body with a } \\
\text { simple PVC handle }\end{array}$ & $\begin{array}{l}\text { Heating of light } \\
\text { chamber } \\
\text { Irregular shadow rings } \\
\text { Fixed single } \\
\text { magnification }\end{array}$ & $\begin{array}{l}\text { Intensity of light improved } \\
\text { for visualising the cervix }\end{array}$ \\
\hline $\begin{array}{l}\text { Third } \\
\text { prototype } \\
(2004)\end{array}$ & $\begin{array}{l}\text { Halogen bulb of } 100 \\
\text { watt with mercury } \\
\text { reflector }\end{array}$ & $\begin{array}{l}\text { Interchangeable lenses } \\
\text { of } 1,2 \text { and } 3 \text { dioptre } \\
\text { values }\end{array}$ & $\begin{array}{l}\text { Aluminium body drilled } \\
\text { with some holes in the } \\
\text { chamber for heat shield. } \\
\text { PVC handle }\end{array}$ & $\begin{array}{l}\text { Lack of a better grip } \\
\text { Lack of a switching } \\
\text { mechanism } \\
\text { Lack of a coherent } \\
\text { beam }\end{array}$ & $\begin{array}{l}\text { Further improvement in } \\
\text { the intensity of light for } \\
\text { visualising the cervix } \\
\text { Provides the choice of } \\
\text { magnification for the users } \\
\text { from } \times 2 \text { to } \times 5 \\
\text { Overheating of the light } \\
\text { chamber was prevented }\end{array}$ \\
\hline $\begin{array}{l}\text { Commercial } \\
\text { model (2009) }\end{array}$ & $\begin{array}{l}\text { Halogen bulb of } 100 \\
\text { watt with mercury } \\
\text { reflector } \\
80 \text {-B Kodak filter with } \\
\text { diffuser lenses were } \\
\text { attached } \\
\text { Die-cast PVC grip with a } \\
\text { miniature switch, which } \\
\text { could be operated with } \\
\text { the right hand thumb }\end{array}$ & $\begin{array}{l}\text { Interchangeable lenses } \\
\text { of } 1,2 \text { and } 3 \text { dioptre } \\
\text { values }\end{array}$ & $\begin{array}{l}\text { Aluminium body drilled } \\
\text { with some more big size } \\
\text { holes in the chamber for } \\
\text { heat shield. PVC handle }\end{array}$ & None & $\begin{array}{l}\text { The light was improved as } \\
\text { a balanced white light } \\
\text { (complete spectrum of } \\
\text { light) } \\
\text { This model was } \\
\text { user-friendly, well } \\
\text { accepted by the users and } \\
\text { was validated } \\
\text { This was the final } \\
\text { commercial version of the } \\
\text { instrument launched by } \\
\text { ICMR }\end{array}$ \\
\hline
\end{tabular}




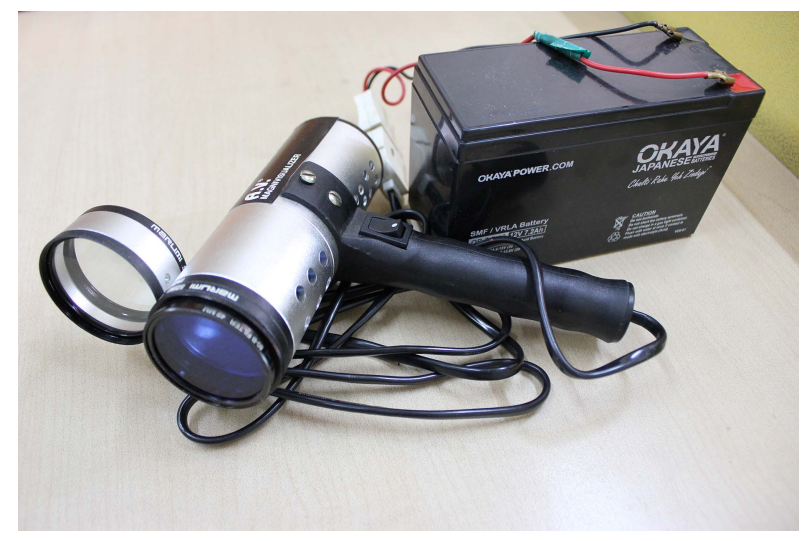

Figure 1 AV Magnivisualizer with battery.

simple PVC handle in the earlier versions), a switching mechanism using the thumb, an 80-B filter with diffuser lenses in order to generate an improved coherent beam of white light so as to avoid any reflection and incorporating a dedicated power supply/charger of the battery, so as to provide electric supply. This final commercial version was named AV Magnivisualizer (figure 1) after the names of the inventor (AP) and the clinical investigator (VS). The word magnivisualizer denotes visualising under magnification. The cost of an AV Magnivisualizer is approximately US $\$ 160$.

\section{OTHER EXISTING OPTICAL SYSTEMS}

The AviScope, a binocular device having 25 green LED (light-emitting diode) lights with $\times 4$ fixed magnification, was introduced and found to have moderate sensitivity and specificity for the confirmation of high-grade cervical lesions in women referred with abnormal cytology. ${ }^{4}$ However, it has its limitations as it emits green light, which has a masking effect in the visualisation of aceto-white lesions. It remained a research tool and never came into regular clinical practice.

The colposcope is the only available instrument used in clinical practice for visualisation of the cervix under magnification $(\times 5$ to $\times 20)$ and a white light source for early detection of precancerous and early cancerous lesions of the cervix. However, it has its own limitations due to its cost (the current price of an optical colposcope in India ranges between US $\$ 8000$ and US\$25 000) and lack of portability; it cannot be used in remote areas with erratic AC power supply and there is a lack of expert manpower (colposcopist). Moreover, it cannot be used as a screening tool as high magnification would lead to the detection of many false positives.

\section{CLINICAL VALIDATION STUDIES OF THE AV MAGNIVISUALIZER}

Table 2 lists all the studies carried out using the AV Magnivisualizer to date. The prototype of the AV Magnivisualizer was initially tested for its efficacy against cytology in 403 women attending a maternal and child health clinic of a tertiary care hospital in Delhi. Screening was carried out using AV Magnivisualizer as a tool for visual inspection with acetic acid under magnification (VIAM) along with

Table 2 Studies published on AV Magnivisualizer

\begin{tabular}{|c|c|c|c|c|c|c|}
\hline $\begin{array}{l}\text { Serial } \\
\text { No }\end{array}$ & Study & Screening & Number & Design & Sensitivity and specificity & Conclusion \\
\hline 1 & Parashari et $a l^{5}$ & $\begin{array}{l}\text { Cervical } \\
\text { cancer }\end{array}$ & $\begin{array}{l}403 \\
\text { symptomatic } \\
\text { women }\end{array}$ & $\begin{array}{l}\text { Magnivisualizer vs } \\
\text { histology }\end{array}$ & $\begin{array}{l}\text { Sensitivity of AV } \\
\text { Magnivisualizer to detect } \\
\text { low-grade lesions was } 57.7 \% \\
\text { vs } 75.3 \% \text { for cytology } \\
\text { Sensitivity for high-grade } \\
\text { lesions was comparable with } \\
\text { both techniques } \\
\text { Specificity of the } \\
\text { magnivisualizer was } 94.3 \% \text { vs } \\
\text { 99\% with cytology }\end{array}$ & $\begin{array}{l}\text { Overall sensitivity and specificity } \\
\text { of the magnivisualizer were } \\
\text { comparable with the cytology }\end{array}$ \\
\hline 2 & Singh et $a l^{3}$ & $\begin{array}{l}\text { Cervical } \\
\text { cancer }\end{array}$ & $\begin{array}{l}385 \\
\text { symptomatic } \\
\text { women }\end{array}$ & $\begin{array}{l}\text { Magnivisualizer vs } \\
\text { yellow light of } \\
\text { tungsten bulb }\end{array}$ & $\begin{array}{l}\text { Correlation with colposcopy: } \\
0.86 \text { for white light vs } 0.53 \\
\text { for yellow light }\end{array}$ & $\begin{array}{l}\text { White light is strongly } \\
\text { recommended for screening } \\
\text { purposes since it enables to select } \\
\text { the correct site of biopsy }\end{array}$ \\
\hline 3 & Singh et $a l^{6}$ & $\begin{array}{l}\text { Cervical } \\
\text { cancer }\end{array}$ & $\begin{array}{l}659 \\
\text { symptomatic } \\
\text { women }\end{array}$ & $\begin{array}{l}\text { Magnivisualizer vs } \\
\text { colposcope }\end{array}$ & $\begin{array}{l}\text { Sensitivity to detect CIN-II and } \\
\text { higher lesions was } 88.3 \% \text { vs } \\
86.7 \% \text { that of colposcopy } \\
\text { Specificity to detect CIN-II and } \\
\text { higher lesions: } 55.8 \% \text { vs } \\
90.4 \% \text { that of colposcopy }\end{array}$ & $\begin{array}{l}\text { Thus, this instrument showed a } \\
\text { better sensitivity to detect CIN-II } \\
\text { and CIN-III lesions compared with } \\
\text { VIA ( } 83 \% \text { vs } 54 \% \text { ) without losing } \\
\text { any specificity }\end{array}$ \\
\hline 4 & Aggarwal et al & $\begin{array}{l}\text { Cervical } \\
\text { cancer }\end{array}$ & $\begin{array}{l}408 \\
\text { symptomatic } \\
\text { women }\end{array}$ & $\begin{array}{l}\text { Magnivisualizer vs } \\
\text { colposcope }\end{array}$ & $\begin{array}{l}\text { The sensitivity and specificity } \\
\text { of magnivisualizer to detect } \\
\text { high-grade lesions were } 95 \% \\
\text { and } 78 \% \text { vs } 86 \% \text { and } 79 \% \\
\text { in the case of a colposcope }\end{array}$ & $\begin{array}{l}\text { AV magnivisualizer can be a } \\
\text { useful alternative when } \\
\text { colposcopy is not available } \\
\text { because of its higher sensitivity } \\
\text { rate and equivalent specificity for } \\
\text { detecting high-grade CIN }\end{array}$ \\
\hline
\end{tabular}


cytological examination in all the women. The results were compared with the gold standard of colposcopy and/or histology. The sensitivity and specificity to detect high-grade lesions with an AV Magnivisualizer was found to be comparable with that of cytology. ${ }^{5}$

Another study was conducted using 659 women attending the gynaecology outpatient department to assess the performance of the AV Magnivisualizer in comparison with the colposcope for detection of precancerous and cancerous lesions of the uterine cervix. ${ }^{6}$ The sensitivity of detection of cervical intraepithelial neoplasia (CIN-II) and higher lesions was $88.3 \%$ for VIAM versus $86.7 \%$ for colposcopy, with a specificity of $55.8 \%$ for VIAM versus $90.4 \%$ for colposcopy. The AV Magnivisualizer was found to be suitable as an illumination device for VIAM for early detection of cervical precancerous and early cancerous lesions of the uterine cervix (table 2).

In addition to its use as screening tool for cervical lesions, two independent groups of workers ${ }^{7}$ evaluated its performance against a colposcope as an evaluation and diagnostic tool. Both the studies confirmed that the AV Magnivisualizer can be used in place of a colposcope in low-resource settings, where the availability of colposcopy facility is difficult.

Further, this instrument was tested for its ease of use. The questionnaire-based survey included 75 doctors and paramedical personnel working in seven different cities of India. The survey revealed that the instrument worked well in different categories of users having different educational and training backgrounds. The performance was highly satisfactory (95-100\%) in clinic and field settings (V Singh, personal communication, 2013).

In a recent editorial, Sankaranarayanan ${ }^{8}$ from the Early Detection and Prevention Section and Screening Group, International Agency for Research on Cancer, Lyon suggested that this device could also be assessed for its possible role in a single visit 'See-and-Treat approach' and for triaging women positive for human papilloma virus (HPV) testing or other screening tests in lower-middle-income countries. The 2015 recommendations from an expert panel, including the author's group, for cancer screening strategies for India also supported novel low-cost visualisation techniques for cervical lesions till a low-cost HPV test is available. ${ }^{9}$

\section{TECHNOLOGY TRANSFER}

A patent has been applied for by the Indian Council of Medical Research, New Delhi for the AV Magnivisualizer. Keeping in mind the potential utilisation and usefulness of its ever-evolving role in screening and evaluation at a very low cost (approximately US $\$ 160$ per piece), the Government of India launched this instrument for widespread use. The technology has already been transferred to a manufacturer for its commercial production.

Further work is under progress to integrate this instrument with an image capturing device for documentation purposes, as well as to transfer the image to a specialist using a mobile or tablet.

Acknowledgement The authors gratefully acknowledge help from Dr. Roopa Hariprasad in preparing the tables.

Contributors AP contributed in the conceptualisation, designing and development of the AV Magnivisualizer. VS participated as a clinical coordinator for the screening of women (VIA, VIAM) using the AV Magnivisualizer for early detection of precancerous and cancer lesions of the cervix and validation of the device. Teaching and training of the medicals and paramedicals using this device. AS was involved in the study design, and analysis and interpretation of the data. RM facilitated the training programme for the use of the AV Magnivisualizer.

Competing interests None declared.

Provenance and peer review Not commissioned; internally peer reviewed.

\section{REFERENCES}

1 Sankaranarayanan R, Esmy PO, Rajkumar R, et al. Effect of visual screening on cervical cancer incidence and mortality in Tamil Nadu, India: a cluster-randomised trial. Lancet 2007;370:398-406.

2 Shastri SS, Mitra I, Mishra GA, et al. Effect of VIA screening by primary health workers: randomized controlled study in Mumbai, India. J Natl Cancer Inst 2014;106:dju009.

3 Singh V, Parashari A, Sehgal A. VIA screening for cervical cancer in developing countries: potential role of light source. J Obstet Gynaecol 2013;33:898-9.

4 Winkler JL, Tsu VD, Bishop A, et al. Confirmation of cervical neoplasia using a hand held, lighted magnification device. Int $J$ Gynecol Obstet 2003;81:35-40.

5 Parashari A, Singh V, Sehgal A, et al. Low-cost technology for screening uterine cervical cancer. Bull World Health Organ 2000;78:964-7.

6 Singh V, Parashari A, Gupta S, et al. Performance of a low cost magnifying device, Magnivisualizer, versus colposcope for detection of pre-cancer and cancerous lesions of uterine cervix. J Gynocol Oncol 2014;25:282-6.

7 Aggarwal P, Batra S, Gandhi G, et al. Can visual inspection with acetic acid under magnification substitute colposcopy in detecting cervical intraepithelial neoplasia in low-resource settings? Arch Gynecol Obstet 2011;284:397-403.

8 Sankaranarayanan R. Magnivisualizer in the early detection of cervical neoplasia. J Gynecol Oncol 2014;25:263-4.

9 Rajaraman P, Anderson BO, Basu P, et al. Recommendations for screening and early detection of common cancers in India. Lancet Oncol 2015;16:e352-61. 